\title{
Development of a Social Activities Scale for Community-Dwelling Older Men Requiring Support in Japan
}

\author{
Michiyo Hirano' ${ }^{1}$ Kazuko Saeki ${ }^{1}$, Izumi Ueda ${ }^{2}$ \\ ${ }^{1}$ Faculty of Health Sciences, Hokkaido University, Hokkaido, Japan \\ ${ }^{2}$ School of Health Sciences, Sapporo Medical University, Hokkaido, Japan \\ Email: micchi_hirano@yahoo.co.jp
}

How to cite this paper: Hirano, M., Saeki, K. and Ueda, I. (2018) Development of a Social Activities Scale for Community-Dwelling Older Men Requiring Support in Japan. Health, 10, 1-12.

https://doi.org/10.4236/health.2018.101001

Received: October 28, 2017

Accepted: January 1, 2018

Published: January 4, 2018

Copyright (๑) 2018 by authors and Scientific Research Publishing Inc. This work is licensed under the Creative Commons Attribution International License (CC BY 4.0).

http://creativecommons.org/licenses/by/4.0/

\section{(c) (i) Open Access}

\begin{abstract}
Aim: We developed a scale to measure the social activities of community-dwelling older men requiring support. Methods: The participants were a group of 134 men, $\geq 65$ years old, who required support and were living in Hokkaido, Japan. An anonymous questionnaire was administered through individual interviews. Valid responses were obtained from 121/134 interviewees. The construct validity of the resulting scale was assessed by exploratory factor analysis (EFA). Criterion-related validity was tested with Spearman's rank correlation test based on the Social Activities Index for Elderly People (SAI-E). Reliability was assessed by Cronbach's alpha. Results. A Social Activities Scale for Community-dwelling Older Men Requiring Support (SASOMS) scale was created, comprised of the following three subscales: daily interactions with familiar people; intimate relationships with family members; and interactions with others through activity programs (e.g., exercise, games, recreation, etc.). The created SASOMS scale correlated with the SAI-E ( $r=$ $0.557)$, and its criterion-related validity was confirmed. The alpha coefficient of the new scale was 0.791 , and its internal consistency was confirmed. Conclusions. The reliability and validity of the developed SASOMS scale was confirmed, demonstrating that it can be used to assess social activities specifically in older men requiring support. Our results suggest that the scale can be used effectively by care providers who support older men requiring care. The usability of the SASOMS should continue to be improved, and it is necessary to verify its validity in longitudinal studies.
\end{abstract}

\section{Keywords}

Instrument Development, Older Men's Health, Social Activities Scale 


\section{Introduction}

A low birthrate is accelerating population aging in Japan to a greater extent than in any other nation in the world. In 2017, persons aged 65 years and older accounted for $27.3 \%$ of the Japanese population [1], and this figure is expected to rise to $38.0 \%$ by 2055 . Of special concern is the expected increase in persons aged 75 years and older [1].

Japan's current policies promote a variety of key service providers, including local residents and private businesses, among others, which promote livelihood support and provide preventive care services for older persons. These policies are designed to encourage participation in social activities to support the maintenance of purpose in daily living [2]. Social activities have been shown to support physical functioning [3], reduce depression [4], and improve life satisfaction among seniors [5]. Social activities are important for both healthy older people and those requiring support. Specifically, among older women requiring support, social activities are thought to deepen positive feelings toward life and to raise their interest in being proactively involved in their own care and disease prevention [6]. For older men requiring support, engagement has been shown to strengthen physical and mental functions [7]. Regarding the existence of sex differences in social behavior [8], older men have been found to have fewer daily interactions with others than women [9], and older men living alone in particular tend to have few ties with their local communities [10].

Social activity scales can be administered by care providers to promote and maintain the social activities of older persons. The Social Activities Index for Elderly People (SAI-E) was developed in 1997 to evaluate social activities among healthy older adults [11], and its validity and reproducibility have been confirmed. Because the SAI-E is less sensitive when administered to older women requiring support, as opposed to healthy women, a social activities scale was developed recently for use in older women requiring support [6] [12].

Because social behavior differs between men and women, it is necessary to develop a social activities scale for men requiring support. To address this need, we developed the Social Activities Scale for Community-dwelling Older Men Requiring Support (SASOMS). This scale can be used together with existing psycho-physical assessments to evaluate social activity participation of elderly men requiring support and it can be used to inform the provision of services appropriate for actual needs.

\section{Methods}

\subsection{Sample and Design}

This study was approved a priori by the Ethics Committee of Hokkaido University Faculty of Health Sciences (June 9, 2016, no. 16 - 24). The participants were men aged 65 years and older men who met the following criteria: 1) certified as requiring level 1 or 2 support for long-term care; and 2) not diagnosed with a cognitive disorder. The target region was three municipalities in Hokkaido, 
northern Japan. Enrollment was based on "population-scale" and "urban or rural" considerations. City A is situated in an urban area, with a population of 120,000 persons, including 33,000 persons aged 65 years and older. Town B and Town Care in outlying regions. Town B has a population of 9,200 persons, with 3,600 persons aged 65 years and older. Town $C$ has a population of 17,000 persons, with 5,400 persons aged 65 years or older [13]. In 2016, the number of persons certified as requiring level 1 or 2 support for long-term care was 2,340 persons in City A, 233 persons in Town B, and 314 persons in Town C [14].

We requested recruitment cooperation from the three municipalities, and 134 people were contacted. The study was explained verbally and in writing to participant by staff at a community general-support center and researchers. Eleven people withdrew from the study due to health reasons or hospitalization.

The survey period was August 2016 to March 2017, with 123 participants. The survey was administered at participants' personal residences. The survey consisted of individual interviews in which respondents' answers were recorded on anonymous questionnaires. To improve inter-rater reliability, the interviews were conducted by certified public health nurses, social workers, care managers, researchers, research assistants with experience as public health nurses, and support center employees. A survey manual clarifying procedures was distributed to all participants beforehand.

\subsection{Measures}

The survey addressed age, living arrangements, required care level, subjective health, and 25 tentative SASOMS items. The SAI-E was used for assessment of criterion-related validity; it has four domains: individual activities, social participation/voluntary activities, learning activities, and work [11].

Tentative SASOMS items were based on the social activities of older men certified as requiring support [7] and a concept analysis of the social activities of older persons in Japan [15]. The items were created after investigation by a research team of persons with research and public health nursing experience. Tentative SASOMS items were classified into 25 items and three concepts: daily interactions with acquaintances, activities at familiar sites in daily life that foster positive feelings and enrich life, and interactions with other persons in services and in activity programs.

A group of seven older men requiring support were asked the following questions: (1) Do scale items reflect the social activities of older men requiring support? and (2) Are scale items easy to understand? Their responses confirmed that the tentative SASOMS items were appropriate as is. A 5-point Likert scale was used for Tentative SASOMS item responses: 5, almost every day; 4, once or more times a week; 3 , once or more times a month; 2 , once or more times a year; and 1 , not at all. Higher scores indicated a higher frequency of social activities.

\subsection{Data Analysis}

Mean values are reported with standard deviations (SDs) to refine scale items, 
we performed the following item analyses: inter-item correlation, comparison mean values \pm SDs, good-poor (G-P) analysis, and item-total (I-T) correlation analyses. G-P analysis divides total scale scores at the mean value into a high group and a low group, and calculates the mean-value difference between these two groups. I-T analysis calculates correlation coefficients between each item and total scale scores of all other items.

The scale's construct and criterion-related validity were examined with exploratory factor analysis (EFA) and concurrent validity analysis, respectively. For the EFA, factor numbers were set using three factors based on the three concepts of social activities engaged in by older men requiring support. The unweighted least-squares method was used with factor loading in the selection of items of 0.35 and above, and a promax rotation was performed. For the concurrent validity analysis, Spearman's rank correlation coefficient was determined between SAI-E and tentative SASOMS items scores. To examine the scale's internal consistency, Cronbach's alpha reliability coefficient was calculated.

Because three communities were targeted, the homogeneity of the respondents was investigated with respect to their residential areas and basic attributes (sex, living arrangements, level of required care, and subjective feelings of health) were examined. Relative distributions of respondent characteristics were analysis with the Mann-Whitney U test, Kruskal-Wallis test, chi-square test, and Fisher's exact test. All statistical analyses were carried out in IBM SPSS $22.0 \mathrm{~J}$ for Windows, with level of significance level of $5 \%$. Alpha coefficients $<0.7$ were considered unsatisfactory [16].

\section{Results}

\subsection{Participants' Attributes}

Analysis was performed on the 121 persons who responded to all of the tentative SASOMS items (response rate, $90.3 \%$ of 134 ). The participants' had a mean age of $81.69 \pm 7.27$ years; their characteristics are summarized in Table 1. Note that a majority of the respondents (57.7\%), considered themselves subjectively to be not so healthy or not healthy (hereinafter, the Unhealthy Group), while a minority (40.6\%) felt they were extremely healthy or healthy (hereinafter, the Healthy Group). Because no significant differences were found with respect to residential area or the other assessed respondent characteristics, the analyses were performed on all three communities (one city and two town designations) combined.

\subsection{Refinement of Tentative SASOMS Items}

The item analysis results are reported in Table 2. No items had a correlation coefficient of 0.8 or above in the inter-item correlation analysis. Ceiling effects were seen for items 6, 7, and 23; floor effects were seen for items 1, 2, 21, and 22 . Item 21 was excluded due to a significant frequency bias (the response rate for one of the response selections exceeded 50\%). The remaining six items with 
Table 1. Participant characteristics $(\mathrm{N}=121)$.

\begin{tabular}{|c|c|c|c|}
\hline Characteristic & Division & $\mathrm{N}$ or mean $\pm \mathrm{SD}$ & $\%$ or range \\
\hline \multirow{2}{*}{ Age, years } & $65-74$ & 25 & 20.7 \\
\hline & $75+$ & 96 & 79.3 \\
\hline \multirow{3}{*}{ Residence } & City A & 95 & 78.5 \\
\hline & Town B & 14 & 11.6 \\
\hline & Town C & 12 & 9.9 \\
\hline \multirow{3}{*}{$\begin{array}{l}\text { Living } \\
\text { arrangements }\end{array}$} & With spouse or children & 77 & 63.7 \\
\hline & Alone & 37 & 30.6 \\
\hline & Other & 7 & 5.8 \\
\hline \multirow{3}{*}{$\begin{array}{l}\text { Long-term } \\
\quad \text { care } \\
\text { certification }\end{array}$} & Level 1 & 50 & 41.3 \\
\hline & Level 2 & 68 & 56.2 \\
\hline & Missing & 3 & 2.5 \\
\hline \multirow{5}{*}{$\begin{array}{l}\text { Subjective } \\
\text { assessment } \\
\text { of health }\end{array}$} & Extremely healthy & 3 & 2.4 \\
\hline & Healthy & 47 & 38.2 \\
\hline & Not so healthy & 57 & 46.3 \\
\hline & Not healthy & 14 & 11.4 \\
\hline & Missing & 2 & 1.6 \\
\hline \multirow{5}{*}{ SAI-E scores } & Social participation/voluntary activities & $0.91 \pm 1.33$ & $0-6$ \\
\hline & Learning activities & $0.20 \pm 0.49$ & $0-4$ \\
\hline & Individual activities & $3.47 \pm 2.00$ & $0-10$ \\
\hline & Work & $0.04 \pm 0.20$ & $0-1$ \\
\hline & Total scale scores & $4.62 \pm 3.16$ & $0-21$ \\
\hline
\end{tabular}

The participants were a group of 134 men, $\geq 65$ years old, who required support and were living in Hokkaido, Japan. The participants met the following criteria: 1) certified as requiring level 1 or 2 support for long-term care; and 2) not diagnosed with a cognitive disorder.

floor or ceiling effects were not excluded because we determined that these items were indispensable for assessment of our concepts of social activities in older men requiring support.

G-P analysis indicated that for all items except 12, 13, and 17, the scores of all participants in the high-score groups were significantly higher than the scores of all participants in the low-score groups (all $p<0.05$ ). In the I-T analysis, for all items except 13 and 17, the correlation coefficient obtained was at least 0.2 . Based on these statistical results, the four items 12, 13, 17, and 21 were excluded.

\subsection{Construct Validity and Criterion-Related Validity of the SASOMS}

As shown in Table 3, the 10-item SASOMS has a three-factor structure. Factor 1, called "daily interactions with familiar people", included five items. Factor 2, called "intimate relationships with family" included three items. Factor 3, called 
Table 2. Item analysis $(\mathrm{N}=121)$.

\begin{tabular}{|c|c|c|c|c|}
\hline Item & Mean & SD & $\begin{array}{c}\text { G-P analysis, } \\
p\end{array}$ & $\begin{array}{l}\text { I-T analysis, } \\
\text { correlation coefficient }\end{array}$ \\
\hline 1. I spend pleasant time with friends. & 2.16 & 1.26 & 0.002 & 0.351 \\
\hline 2. I share my status with friends through letters and phone calls. & 1.98 & 1.10 & 0.001 & 0.343 \\
\hline 3. I speak with persons in the neighborhood and get information. & 2.49 & 1.38 & $<0.001$ & 0.559 \\
\hline 4. Neighborhood persons speak to me in a friendly way. & 2.92 & 1.31 & $<0.001$ & 0.507 \\
\hline 5. I am on friendly terms with neighborhood persons. & 2.41 & 1.41 & $<0.001$ & 0.572 \\
\hline $\begin{array}{l}\text { 6. I spend time relaxing with family members who either live } \\
\text { with me or elsewhere. }\end{array}$ & 3.57 & 1.54 & $<0.001$ & 0.447 \\
\hline 7. I spend pleasant time with family through meals, chatting, etc. & 3.62 & 1.55 & $<0.001$ & 0.501 \\
\hline 8. Family members and relatives help me with daily tasks. & 3.24 & 1.66 & $<0.001$ & 0.364 \\
\hline 9. I share my status via telephone calls with family and relatives. & 2.69 & 1.17 & 0.001 & 0.353 \\
\hline $\begin{array}{l}\text { 10. I share my status via letters and New Year's postcards with } \\
\text { family and relatives. }\end{array}$ & 1.88 & 0.57 & 0.001 & 0.306 \\
\hline 11. I share things with family with the aim of experiencing pleasure. & 1.79 & 0.76 & 0.001 & 0.288 \\
\hline $\begin{array}{l}\text { 12. Separately living family and relatives come to my residence to } \\
\text { see how I am doing. }\end{array}$ & 2.83 & 1.16 & 0.069 & 0.255 \\
\hline 13. I enjoy friendly chatting about various things with care providers. & 3.55 & 0.88 & 0.646 & 0.036 \\
\hline 14. I enjoy friendly chatting about various things with healthcare workers. & 2.56 & 0.89 & 0.017 & 0.307 \\
\hline 15. Doctors provide me with advice about daily life, therapy, etc. & 2.60 & 0.79 & $<0.001$ & 0.401 \\
\hline 16. Care providers provide me with necessary information about illness. & 2.59 & 1.25 & $<0.001$ & 0.359 \\
\hline 17. Regular interactions with care providers give me a sense of security. & 3.20 & 1.15 & 0.215 & 0.101 \\
\hline $\begin{array}{l}\text { 18. I view the activities and status of participants at my day service center, } \\
\text { clubs for older persons, hobby group, etc. }\end{array}$ & 2.86 & 1.42 & $<0.001$ & 0.344 \\
\hline $\begin{array}{l}\text { 19. I enjoy conversations with participants at my day service center, } \\
\text { older persons' club, hobby group, etc. }\end{array}$ & 2.61 & 1.46 & $<0.001$ & 0.384 \\
\hline $\begin{array}{l}\text { 20. I send letters and New Year's postcards back and forth with former } \\
\text { work associates. }\end{array}$ & 1.64 & 0.51 & 0.002 & 0.267 \\
\hline 21. I meet and talk with former work associates. & 1.32 & 0.64 & - & - \\
\hline $\begin{array}{l}\text { 22. If an acquaintance, etc., has a problem or issue, I do as much as } \\
\text { I can to help. }\end{array}$ & 1.93 & 1.07 & $<0.001$ & 0.390 \\
\hline $\begin{array}{l}\text { 23. I gain a sense of the daily life and movements of society from the } \\
\text { streets and the scenery of my town and surroundings. }\end{array}$ & 3.40 & 1.64 & $<0.001$ & 0.247 \\
\hline 24. I read for pleasure and knowledge. & 2.61 & 1.75 & 0.007 & 0.237 \\
\hline 25. I enjoy hobbies at my own house. & 2.95 & 1.79 & $<0.001$ & 0.421 \\
\hline
\end{tabular}

$\dagger$ Independent $\mathrm{t}$-test. $\ddagger$ Between each item and total scale scores of all other items. 
Table 3. Factor loadings and factor structure of the SASOMS $(\mathrm{N}=121, \alpha=0.791)$.

\begin{tabular}{|c|c|c|c|}
\hline \multirow{2}{*}{ Item } & \multicolumn{3}{|c|}{ Factor loading } \\
\hline & Factor 1 & Factor 2 & Factor 3 \\
\hline \multicolumn{4}{|l|}{ Factor 1: Daily interactions with familiar people, $\alpha=0.802$} \\
\hline 5. I am on friendly terms with neighborhood persons. & 0.854 & 0.062 & -0.008 \\
\hline 3. I speak with persons in the neighborhood and get information. & 0.828 & 0.039 & -0.029 \\
\hline 4. Neighborhood persons speak to me in a friendly way. & 0.779 & -0.051 & 0.030 \\
\hline 1. I spend pleasant time with friends. & 0.475 & -0.071 & 0.100 \\
\hline 2. I share my status with friends through letters and phone calls. & 0.409 & -0.011 & -0.096 \\
\hline \multicolumn{4}{|l|}{ Factor 2: Intimate relationships with family, $\alpha=0.849$. } \\
\hline 6. I spend time relaxing with family members who either live with me or elsewhere. & -0.065 & 0.944 & 0.029 \\
\hline 7. I spend pleasant time with family through meals, chatting, etc. & 0.057 & 0.843 & -0.011 \\
\hline 8. Family members and relatives help me with daily tasks. & -0.016 & 0.660 & 0.009 \\
\hline \multicolumn{4}{|l|}{ Factor 3 : Interactions with others through activity programs, $\alpha=0.841$. } \\
\hline $\begin{array}{l}\text { 18. I enjoy conversations with participants at my day service center, older persons' club, } \\
\text { hobby group, etc. }\end{array}$ & 0.017 & -0.038 & 1.009 \\
\hline $\begin{array}{l}\text { 19. I view the activities and status of participants at my day service center, clubs for older } \\
\text { persons, hobby group, etc. }\end{array}$ & -0.039 & 0.067 & 0.709 \\
\hline Factor contribution: & 2.789 & 2.378 & 1.868 \\
\hline
\end{tabular}

"interactions with others through activity programs" included two items. Respective contribution rates of these three factors were $32.68 \%, 15.13 \%$, and $12.34 \%$, respectively, with a cumulative contribution rate of $60.15 \%$. Criterion-related validity analysis demonstrated that all three SASOMS factors correlated moderately with the individual activities domain of the SAI-E. Meanwhile, factor 1 correlated moderately with the social participation/volunteer activities domain and correlated, albeit not as strongly, with the learning activities domain of the SAI-E. The two scales, on the whole, were found to be well correlated. The Spearman's rank correlation coefficients and associated significance levels for all correlations between these two scales and their domains/factors are reported in Table 4.

\subsection{SASOMS Reliability}

For the SASOMS overall, we obtained a Cronbach's alpha reliability coefficient value of 0.791 , thus demonstrating internal consistency. The Cronbach's alpha values for factor 1 , factor 2 , and factor 3 were $0.802,0.849$, and 0.841 , respectively. Regarding the relationship between respondent attributes and SASOMS score, as shown in Table 5, persons aged 75 years and older had significantly higher factor 1 scores than those aged 65 - 74 years and persons living with family had significantly higher factor 2 scores and scale total score than those who were living independently. 
Table 4. SASOMS factor and total score correlations with SAI-E domain and total scores $(\mathrm{N}=121)$.

\begin{tabular}{ccccc}
\hline \multirow{2}{*}{ SAI-E } & \multicolumn{3}{c}{ SASOMS } \\
\cline { 2 - 5 } & Factor 1 & Factor 2 & Factor 3 & Total score \\
\cline { 2 - 5 } Individual activities & $0.506^{* *}$ & $0.295^{* *}$ & $0.328^{* *}$ & $0.537^{* *}$ \\
Social participation/volunteer activities & $0.448^{* *}$ & 0.086 & 0.115 & $0.367^{* *}$ \\
Learning activities & $0.203^{*}$ & 0.060 & 0.046 & $-0.191^{*}$ \\
work & -0.086 & 0.026 & -0.035 & 0.057 \\
Total score & $0.564^{* *}$ & $0.268^{* *}$ & $0.285^{* *}$ & $0.557^{* *}$ \\
\hline
\end{tabular}

${ }^{*} p<0.05,{ }^{* *} p<0.01$, Spearman's rank correlation coefficient.

Table 5. Relationship between respondent characteristics and SASOMS factors $(\mathrm{N}=121)$.

\begin{tabular}{|c|c|c|c|c|c|c|c|c|c|c|c|c|c|}
\hline \multirow{2}{*}{ Characteristic } & \multirow{2}{*}{$\mathbf{N}$} & \multicolumn{3}{|c|}{ Factor 1} & \multicolumn{3}{|c|}{ Factor 2} & \multicolumn{3}{|c|}{ Factor 3} & \multicolumn{3}{|c|}{ Total score } \\
\hline & & Mean $\pm S D$ & Median & $P \dagger$ & Mean $\pm S D$ & Median & $P \dagger$ & Mean $\pm S D$ & Median & $P \dagger$ & Mean $\pm S D$ & Median & $P \dagger$ \\
\hline $65-74$ & 25 & $10.04 \pm 4.57$ & 10.00 & 0.028 & $9.00 \pm 5.06$ & 9.00 & 0.127 & $4.88 \pm 2.68$ & 5.00 & 0.217 & $23.92 \pm 8.60$ & 24.00 & 0.014 \\
\hline $75+$ & 96 & $12.46 \pm 4.81$ & 12.00 & & $10.08 \pm 3.83$ & 11.00 & & $5.63 \pm 2.67$ & 7.00 & & $28.89 \pm 8.01$ & 29.00 & \\
\hline \multicolumn{14}{|c|}{ Living arrangements } \\
\hline $\begin{array}{l}\text { With spouse } \\
\text { or children }\end{array}$ & 77 & $12.29 \pm 4.26$ & 12.00 & 0.065 & $11.77 \pm 3.69$ & 13.00 & $<0.001$ & $5.83 \pm 2.66$ & 8.00 & 0.192 & $29.88 \pm 7.27$ & 30.00 & 0.001 \\
\hline Alone & 37 & $11.05 \pm 6.00$ & 9.00 & & $7.76 \pm 3.80$ & 8.00 & & $4.97 \pm 2.87$ & 5.00 & & $23.78 \pm 9.07$ & 22.00 & \\
\hline \multicolumn{14}{|c|}{ Certified support level } \\
\hline Level 2 & 68 & $12.10 \pm 5.30$ & 11.00 & & $10.38 \pm 3.89$ & 11.00 & & $5.59 \pm 2.65$ & 6.50 & & $28.07 \pm 8.81$ & 28.00 & \\
\hline
\end{tabular}

$†$ †ann-Whitney U-test. $\ddagger$ Analysis target excludes “other” and “missing”.

\section{Discussion}

We measured the social activities of older men requiring support, and developed a 10-item, three-factor scale. Because the resultant SASOMS items were created based on prior research [7] [15] and by a research team comprised of persons with research and public health nursing experience, these items are thought to reflect concretely the participants' actual social activities.

The SASOMS had more concrete social activity items than the SAI-E. That is, the SASOMS appears to be an effective scale for measuring the unique social activities of older men requiring support, activities that are not measured directly by scales that measure the social activities of healthy older people. The participants in the present study had considerably lower scores than those of a prior survey of 1,500 randomly selected older adults in Japan, in which older men obtained SAI-E scores of 1.7 for participation/volunteer activities, 0.5 for learning activities, and 6.9 for individual activities [17]. Hence, our results indicate that the sensitivity of the SAI-E is diminished when applied to older men requiring support, demonstrating the need for a scale that can better measure this group's 
actual social activities.

Previously, the social activities domain of the SAI-E has been defined as "human interactions fostered through interaction with other persons in society and the local community" [18]. Social activity-related experiences are proactive engagements involving interactions with others, such as visiting or being visited by friends, going to movies, dining out, informal or formal participation in groups, employment, volunteer activities, and going to religious services [19] [20]. The SASOMS items query repeated interactions that one has in daily life with friends and acquaintances, family, and other persons one meets in various group settings, including interest clubs and daily care service sites. Compared with prior research, these interactions are relatively limited. For instance, although a social activities scale for older women requiring support includes personal activities, such as cooking and consultations with various specialists [6] [12], no such items are in the SASOMS. Thus, the SASOMS is limited in terms of activities and interpersonal interactions compared with social activity scales for healthy older people, and it does not include items specific to women.

Regarding content validity, although the factor structure correlated with the conceptual framework that the scale was based on, adopted items were reduced by around half. Items eliminated because of the factor analysis results addressed activities performed by an individual alone and those involving interactions with healthcare workers and care providers. These items had a weak relationship with our stated concepts. Regarding criterion-related validity, the SASOMS correlated significantly with the SAI-E, and among the SAI-E domains, with the individuals' activities domain most robustly [11]. Relative to the SAI-E, the SASOMS measures concepts that are more closely related to personal activities and social participation/volunteer activities. The SASOMS did not correlate robustly with the learning activities $(r=0.191)$ or work $(r=-0.057)$ domains of the SAI-E. These results are consistent with prior findings for the social activities of older women requiring support [6] [12]. Regarding reliability, the internal consistency of the SASOMS met the required threshold, thus confirming acceptable reliability.

The inherent decline in the instrumental activities of daily living of older persons requiring support obliges a change in the kind of social activities they engage in. SASOMS factors 1 - 3 correlated with the individual activities domain of the SAI-E, and factor 1, in particular, correlated moderately with the social participation/volunteer activities of the SAI-E, indicating that the SASOMS is conceptually similar to the individual activities and social participation/volunteer activities domains of the SAI-E.

Our analysis of SASOMS scores in terms of ages and living arrangements revealed an effect of older age ( $>75$ years) on factor 1 scores. Japanese people in their early $70 \mathrm{~s}$ and early $80 \mathrm{~s}$ are known to have more intimate acquaintances with neighbors than their 65 - 69-years-old compatriots [21]; we believe that a similar trend was reflected in our study. Meanwhile, persons aged 75 and older tend to have less interactions with friends and acquaintances than persons aged 
74 and younger [22]. Factor-1 items about interactions with friends were not limited to direct meetings, but also included indirect communications in the item, "I share my status with friends through letters and phone calls". For this reason, factor 1 scores of persons aged 75 years and older are expected to be high. This issue should be investigated further.

Notably, men living with family had higher scores for "intimate relationships with family" and higher SASOMS total scores than those living alone. In a nationwide survey in Japan [23], the percentage of persons who said they "have no one [they] can rely on" for required assistance was $2.4 \%$ overall, but $20 \%$ among men living alone. In addition, $28 \%$ of men living alone had less than one phone call or email-based conversation every two to three days [23]. One surmises that persons living alone have fewer intimate interactions with others compared with persons living with family, and that their intimate relationships with family members who do not live together are also comparatively low.

The social activities of healthy older people tend to favor items 3 - 6 (see Table 3), whereas for older men requiring support, items 1 - 2 are also important social activities. Care providers must understand the activity levels of the men they are caring for in their provision of support. If care providers set targets at levels appropriate for healthier older people, the services they provide may not be a good fit for the physical abilities, mental abilities, and social activity needs of older men requiring support.

This study had some limitations. First, our small sample size and specific communities surveyed limits the generalizability the results. Second, although the reliability and validity of the SASOMS was verified, its usability should be verified by future studies. Third, due to time limitations, we did not verify predictive validity or responsiveness in the analysis strategy. Future longitudinal studies are needed to further verify the validity of this scale.

\section{Conclusion}

In conclusion, the SASOMS should be effective in the provision of support by care providers for older men requiring support. First, it can be used by care providers to measure the characteristics of social activities of older men requiring support. Scale total scores measure the overall activities of such men, while comparison of the ratios for scores across the three subscales can demonstrate their specific social activities. Second, when the SASOMS is used together with activities of daily living and instrumental activities of daily living assessments, one can better investigate the living-activity interventions required by older men requiring support. Use of the SASOMS may thus help to expand the scope of daily life and improve quality of life. Third, the SASOMS can be used to monitor intervention efficacy because it measures the effects of social activities-related support provided for older men requiring support.

\section{Conflict of Interests}

The authors declare that they have no conflict of interest. 


\section{Funding}

This work was supported by JSPS KAKENHI Grant Number JP26463548.

\section{References}

[1] Cabinet Office, Government of Japan (2017) Annual Report on the Aging Society 2017. http://www8.cao.go.jp/kourei/whitepaper/w-2017/zenbun/29pdf_index.html

[2] Ministry of Health, Labour and Welfare (2017) Kaigoyobou-Nichijyouseikatsushiensougoujigyo.

http://www.mhlw.go.jp/file/06-Seisakujouhou-12300000-Roukenkyoku/0000088276 .pdf

[3] Saito, E., Takai, J., Kanazawa, K., Honda, A. and Saeki, K. (2004) Changes in Functional Capacity in Older Adults Living Alone: A Three-Year Longitudinal Study in a Rural Area of Japan. Japanese Journal of Public Health, 51, 958-968.

[4] Demura, S. and Sato, S. (2003) Relationships between Depression, Lifestyle and Quality of Life in the Community Dwelling Elderly: A Comparison between Gender and Age Group. Journal of Physiological Anthropology and Applied Human Science, 22, 159-166. https://doi.org/10.2114/jpa.22.159

[5] Okamoto, H. (2008) Effects of Social Activities on Life Satisfaction among the Elderly: Four Aspects in Men and Women. Japanese Journal of Public Health, 55, 388-395. (In Japanese)

[6] Hirano, M., Kawahara, K. and Saeki, K. (2014) Development of a Scale to Measure the Social Activities of Older Women Requiring Daily Support. Journal of Japan Academy of Community Health Nursing, 17, 19-27. (In Japanese)

[7] Hirano, M., Saeki, K., Ueda, I., Honda, H. and Mizuno, Y. (2017) Social Activities of Older Men Who Require Daily Support and the Purpose of Such Activities. Japanese Journal of Public Health, 64, 14-24. (In Japanese)

[8] Gagliardi, C., Spazzafumo, L., Marcellini, F., Mollenkopf, H., Ruoppila, I., Tacken, M. and Szemann, A. (2007) The Outdoor Mobility and Leisure Activities of Older People in Five European Countries. Ageing \& Society, 27, 683-700. https://doi.org/10.1017/S0144686X07006198

[9] Sawaoka, S., Koyano, W. and Honda, A. (2012) Everyday Interactions with Others among the Old-Old Living Alone in an Urban Area. Japanese Journal of Gerontology, 34, 39-45. (In Japanese)

[10] Kono, A. and Tadaka, E. (2012) Daitoshi ni kurasu dokkyodanseikoureisya no seikatsukadai to jiritsushien. Koushu Eisei, 76, 702-705. (In Japanese)

[11] Hashimoto, S., Aoki, R., Tamakoshi, A., Shibazaki, S., Nagai, M., Kawakami, N., Ikari, A., Ojima, T. and Ohno, Y. (1997) Development of Index of Social Activities for the Elderly. Japanese Journal of Public Health, 44, 760-768. (In Japanese)

[12] Hirano, M., Kawahara, K. and Saeki, K. (2015) Development of a Social Activities Scale for Community-Dwelling Older Women Requiring Support in Japan: A Preliminary Study. Public Health Nurse, 32, 508-516.

https://doi.org/10.1111/phn.12161

[13] Department of Health and Welfare, Hokkaido (2015) Hokkaido no koureisyajinkou no jyoukyo. http://www.pref.hokkaido.lg.jp/hf/khf/koureishajinkou.htm

[14] Ministry of Health, Labour and Welfare (2016) Kaigohokenjigyou jyoukyouhoukok. http://www.mhlw.go.jp/topics/kaigo/osirase/jigyo/m16/1606.html

[15] Hirano, M. (2011) "Social Activity of Elderly" in Japan: Concept Analysis. The 
Journal of Japan Academy of Health Sciences, 14, 121-128. (In Japanese)

[16] Burns, N. and Grove, S.K. (2007) The Practice of Nursing Research: Conduct, Critique, and Utilization. Elsevier Japan Inc., Tokyo, 491.

[17] Okamoto, H., Okada, S. and Shirasawa, M. (2006) Factors Associated with Social Activities among the Elderly in a Metropolitan Area: Physical, Psychological, and Socio-Environmental Parameters. Japanese Journal of Public Health, 53, 504-515. (In Japanese)

[18] Levasseur, M., Richard, L., Gauvin, L. and Raymond, E. (2010) Inventory and Analysis of Definitions of Social Participation Found in the Aging Literature: Proposed Taxonomy of Social Activities. Social Science \& Medicine, 71, 2141-2149. https://doi.org/10.1016/j.socscimed.2010.09.041

[19] Willie-Tyndale, D., Holder-Nevins, D., Mitchell-Fearon, K. and Eldemire-Shearer, D. (2016) Participation in Social Activities and the Association with Socio-Demographic and Health-Related Factors among Community-Dwelling Older Adults in Jamaica. Journal of Cross-Cultural Gerontology, 31, 427-447. https://doi.org/10.1007/s10823-016-9297-x

[20] Hong, S.I., Hasche, L. and Bowland, S. (2009) Structural Relationships between Social Activities and Longitudinal Trajectories of Depression among Older Adults. Gerontologist, 49, 1-11. https://doi.org/10.1093/geront/gnp006

[21] Cabinet Office, Government of Japan (2010) Results of Survey on the Senior Citizens Attitude toward Housing and the Living Environment 2010. http://www8.cao.go.jp/kourei/ishiki/h22/sougou/zentai/pdf/2-1.pdf

[22] Saito, T., Kondo, K., Murata, C., Jeong, S., Suzuki, K. and Kondo, N. (2015) Gender and Regional Differences in Going-Out, Social, and Leisure Activities among Older Adults. Findings from the JAGES Project. Japanese Journal of Public Health, 62, 596-608. (In Japanese)

[23] Cabinet Office, Government of Japan (2015) Annual Report on the Aging Society 2015. http://www8.cao.go.jp/kourei/whitepaper/w-2015/html/zenbun/s1_2_6.html 